\title{
The diagnostic role of diffusion-weighted magnetic resonance imaging in hypopharyngeal carcinoma
}

\author{
SI-CONG ZHANG ${ }^{1,2^{*}}$, SHUI-HONG ZHOU ${ }^{1 *}$, DE-SHENG SHANG ${ }^{3}$, YANG-YANG BAO ${ }^{1}$, \\ LING-XIANG RUAN ${ }^{3}$ and TING-TING WU ${ }^{1}$ \\ ${ }^{1}$ Department of Otolaryngology, The First Affiliated Hospital, College of Medicine, Zhejiang University, \\ Hangzhou, Zhejiang 310003; ${ }^{2}$ Department of Otolaryngology, People's Hospital of Cixi City, \\ Cixi, Zhejiang 315300; ${ }^{3}$ Department of Radiology, The First Affiliated Hospital, College of Medicine, \\ Zhejiang University, Hangzhou, Zhejiang 310003, P.R. China
}

Received August 7, 2016; Accepted December 29, 2017

DOI: $10.3892 / \mathrm{ol} .2018 .8053$

\begin{abstract}
The aim of the present study was to assess the role of diffusion-weighted magnetic resonance imaging (DWI) and apparent diffusion coefficient (ADC) values in hypopharyngeal carcinoma. A total of 40 hypopharyngeal carcinoma tissues and 15 benign lesion tissues were retrospectively analyzed. DWI, and T1- and T2-weighted magnetic resonance imaging (MRI) was performed. The sensitivity, specificity and accuracy of conventional MRI were 97.5, 66.7, and 89.1\%, respectively. The mean ADC value [diffusion sensitive factor $(\mathrm{b})=1,000 \mathrm{x} \mathrm{sec} / \mathrm{mm}^{2}$ ) for hypopharyngeal carcinomas was $(1.0285 \pm 0.0328) \times 10^{-3} \mathrm{~mm}^{2} / \mathrm{sec}$, which was significantly lower than the mean ADC value for benign lesions $\left[(1.5333 \pm 0.1061) \times 10^{-3} \mathrm{~mm}^{2} / \mathrm{sec} ; \mathrm{P}<0.001\right]$. Receiver operating characteristic (ROC) curve analysis revealed that the area under the curve (AUC) was 0.921 while the optimal threshold for the cut-off point of the ADC was $1.075 \times 10^{-3} \mathrm{~mm}^{2} / \mathrm{sec}$. The mean ADC value of the metastatic nodes was $(0.9184 \pm 0.0538) \times 10^{-3} \mathrm{~mm}^{2} / \mathrm{sec}$, lower than the mean value for the benign nodes $\left[(1.2538 \pm 0.1145) \times 10^{-3} \mathrm{~mm}^{2} / \mathrm{sec}\right.$; $\mathrm{P}=0.005]$. Two groups were created according to the mean of the ADC valueofhypopharyngealcarcinomas $[\leq(1.0285 \pm 0.0328)$ $\mathrm{x} 10^{-3} \mathrm{~mm}^{2} / \mathrm{sec}$ vs. $\left.>(1.0285 \pm 0.0328) \times 10^{-3} \mathrm{~mm}^{2} / \mathrm{sec}\right]$. The 2-year survival rates of the two groups were 55.6 and $100.0 \%$, respectively $(\mathrm{P}=0.024)$. ADC values may aid in distinguishing hypopharyngeal carcinomas from benign lesions and
\end{abstract}

Correspondence to: Mr. De-Sheng Shang, Department of Radiology, The First Affiliated Hospital, College of Medicine, Zhejiang University, 79 Qingchun Road, Hangzhou, Zhejiang 310003, P.R. China

E-mail: 13868060120@163.com

*Contributed equally

Key words: hypopharyngeal carcinoma, diffusion-weighted magnetic resonance imaging, apparent diffusion coefficient, prognosis differentiating metastatic lymph nodes of hypopharyngeal squamous cell carcinomas from reactive cervical lymph nodes. In conclusion, mean ADC values may be useful prognostic factors in univariate analysis of hypopharyngeal carcinoma.

\section{Introduction}

Hypopharyngeal carcinoma has one of the poorest prognoses of all head and neck carcinomas as it is frequently diagnosed at an advanced stage and exhibits aggressive and distant metastasis (1). Although there have been significant advancements in surgical techniques and chemoradiotherapy recently, the prognosis of hypopharyngeal carcinoma remains unsatisfactory (2).

At present, the most common diagnostic tools include different types of laryngoscopy, computed tomography (CT), and routine magnetic resonance imaging (MRI). CT may reveal the extent of infiltration of hypopharyngeal carcinoma, but it also has certain limitations, including over estimation of invasion of the vocal cords, underestimation of invasion of the upper esophagus, difficulty in displaying mild invasion of thyroid cartilage, and uncertainty with regard to the normal size of the cervical lymph nodes and whether they are subject to metastasis. Routine MRI has high resolution in soft tissue, enabling it to accurately determine the infiltration extent of tumors; however, it remains a challenge to diagnose small lesions or micrometastatic nodes (3). Positron emission tomography (PET) and PET/CT may supply functional information and differentiate malignant tumors from benign lesions; however, they are expensive with low availability and are limited by relatively low spatial resolution and risk of radiation exposure (3).

Recently, diffusion-weighted MRI (DWI) has emerged as a relatively novel functional imaging tool that records the molecular motion of protons corresponding to Brownian motion within living tissue (4). The extent of molecular diffusion may be estimated and quantified in terms of the apparent diffusion coefficient (ADC) (5). DWI is widely used in clinical practice to differentiate benign masses from malignant tumors, to diagnose lymph node metastasis, to detect recurrent lesions following radiotherapy/chemotherapy, and to predict the effect 
of treatment using DWI and ADC values. DWI is able to detect changes in tumor size and shape prior to them becoming visible to the naked eye, and the ADC value is affected by cell size, density and integrity (6).

Initially, DWI was primarily used in neurology to identify intracranial lesions. However, the complex anatomical structure and functions occurring in the head and neck, including respiration, swallowing and phonation, limit the use of DWI in these regions. Nonetheless, with the advances in MRI technical performance and MRI machinery, the application of DWI to head and neck oncology is increasing $(7,8)$. Head and neck cancer occurs at multiple sites, including the oral cavity, oropharynx and larynx $(9,10)$. Recently, Driessen et al (10) used single-shot spin-echo echo-planar DWI of 1.5T MRI to investigate the association between histological characteristics of laryngeal and hypopharyngeal squamous cell carcinoma and ADC values (10). However, to the best of our knowledge, few previous studies have investigated the role of DWI at a single site in the head and neck regions. To the best of our knowledge, our previous study was the first to successfully use DWI and 3.0-T MRI to differentiate preoperative laryngeal carcinomas from precursor lesions (11), and there have been no previous studies regarding the use of ADC values and single-shotecho-planar imaging sequence (EPI) of 3.0-T MRI alone in hypopharyngeal carcinoma.

The aim of the present study was to assess the role of DWI and ADC values in hypopharyngeal carcinoma in order to determine: i) Whether ADC has diagnostic value in discriminating carcinomas from benign lesions, or discriminating metastatic lymph nodes from reactive cervical lymph nodes; and ii) whether ADC values are associated with the prognosis of hypopharyngeal carcinomas.

\section{Materials and methods}

Patients. The present study was approved by the Institutional Review Board of the First Affiliated Hospital, College of Medicine, Zhejiang University, Hangzhou, China (IRB no. 2015428), and written informed consent was obtained from all enrolled patients.

Between June 2012 and July 2015, patients with hypopharyngeal lesions who had undergone preoperative laryngostroboscopy (Endo-stroboscope L; Atmos Medizin Technik GmbH \& Co. KG, Lenzkirch, Germany) and DWI were considered for inclusion in the present study. The inclusion criteria were as follows: i) Suspicious lesions in the hypopharynx on laryngostroboscopy; ii) 3.0-T MRI (including DWI, $b=0$ and $1,000 \mathrm{sec} / \mathrm{mm}^{2}$ ) prior to treatment; iii) surgery, concurrent chemo-radiotherapy (CCR) and pathological confirmation of diagnoses (including frozen sections and routine pathological results); and iv) availability of complete clinical data. Exclusion criteria were as follows: i) Incomplete clinical data; ii) 3.0-T MR without DWI prior to treatment; iii) undetermined Tumor-Node-Metastasis (TNM) stage of hypopharyngeal carcinoma (11) or recurrent hypopharyngeal carcinoma requiring a second surgery.

Consequently, 63 patients (62 males and 1 female) were included. The mean age of was 55.3 years (range, $30-81$ years). Of these patients, 4 were excluded owing to susceptibility artifacts (due to linear blurring, geometric distortion or imaging distortion) that compromised image quality. A total of 4 patients, who waived any treatment, were also excluded. In the remaining 55 patients, pathological results revealed 40 cases of hypopharyngeal carcinoma (Table I) and 15 benign lesions. In cases where a suspicious mass at the primary site or a neck mass was observed on physical examination or CT/MRI, a biopsy or needle biopsy was performed. The tumor volume (TV) of samples was calculated as follows: TV=XxYxZ/2 (X, greatest length; Y, greatest width and Z, greatest depth of tumor samples). Patients were followed up every 1 month over the first year, every 3 months over the second year, every 6 months over the next 3 years and annually thereafter. The last follow-up date was March 2015.

MRI protocol. All MRI examinations were performed using a 3.0-T MRI scanner (Philips Achieva ${ }^{\circledR}$ 3.0T; Royal Philips Electronics, Amsterdam, Netherlands) with a 16-channel head and neck coil. Conventional MRI included an axial T1-weighted turbo spin echo (TSE) sequence with the following parameters (11): Slice thickness, $4 \mathrm{~mm}$; 24 slices; intersection gap, $1 \mathrm{~mm}$; repetition time/echo time (TR/TE), $450 \mathrm{~ms} / 10 \mathrm{~ms}$; matrix, 320x224; field of view (FOV), 240x180 mm; and an axial T2-weighted TSE sequence (slice thickness, $4 \mathrm{~mm}$; 24 slices; intersection gap, $1 \mathrm{~mm}$; TR/TE, $400 \mathrm{~ms} / 10 \mathrm{~ms}$; matrix, 320x224; FOV, 240x180 mm). The coronal T2-weighted TSE sequence included the following parameters: Slice thickness, $4 \mathrm{~mm}$; 24 slices; intersection gap, $1 \mathrm{~mm}$; TR/TE, 400 ms/10 ms; matrix 320x224; FOV, 240x220 mm; and two signals were acquired, covering the larynx. Following gadolinium injection, T1-weighted fat-saturated sequences were performed in the axial plane (using identical parameters to pre-contrast medium administration) and in the coronal plane (24 slices; slice thickness, $4 \mathrm{~mm}$; intersection gap, $1 \mathrm{~mm}$; TR/TE, 540 ms/9.2 ms; matrix, 320x224; FOV, 240x220 mm; and two signals were acquired using fat suppression).

DWI was performed with a single-shot EPI-DWI). The parameters were as follows: TR/TE, 8,000 ms/60 ms; FOV, 240x240 mm; matrix, 124x124; 24 slices; slice thickness, $4 \mathrm{~mm}$; and $\mathrm{b}=0$ or $1,000 \mathrm{sec} / \mathrm{mm}^{2}$ ). ADC maps were generated using Extended MR Workspace (EWS). In order to minimize susceptibility artifacts, the patients were encouraged not to swallow, speak or cough during imaging. In addition, thin slices were obtained, meticulous shimming was applied and sight fixation (to steady the patient's head) were used.

Image analysis. The imaging data were reviewed by two radiologists from the Department of Radiology (the First Affiliated Hospital, Zhejiang University, Hangzhou, P.R. China) with specific experience in head and neck imaging, but with no knowledge of the primary lesion. They reached an agreed opinion prior to reviewing the pathology results. The lesion contour, size and internal architecture were documented. An ADC map was generated by DWI with EWS and the ADC value was measured.

All hypopharyngeal lesions were characterized based on the signal intensity in T1- and T2-weighted MRIs and enhancement characteristics. DW-MRI at a native b-value of $1,000 \mathrm{sec} / \mathrm{mm}^{2}$ (b-1,000 images) and the corresponding ADC maps were matched to and evaluated with the morphological images as previously described (11). A hyperintense signal on 


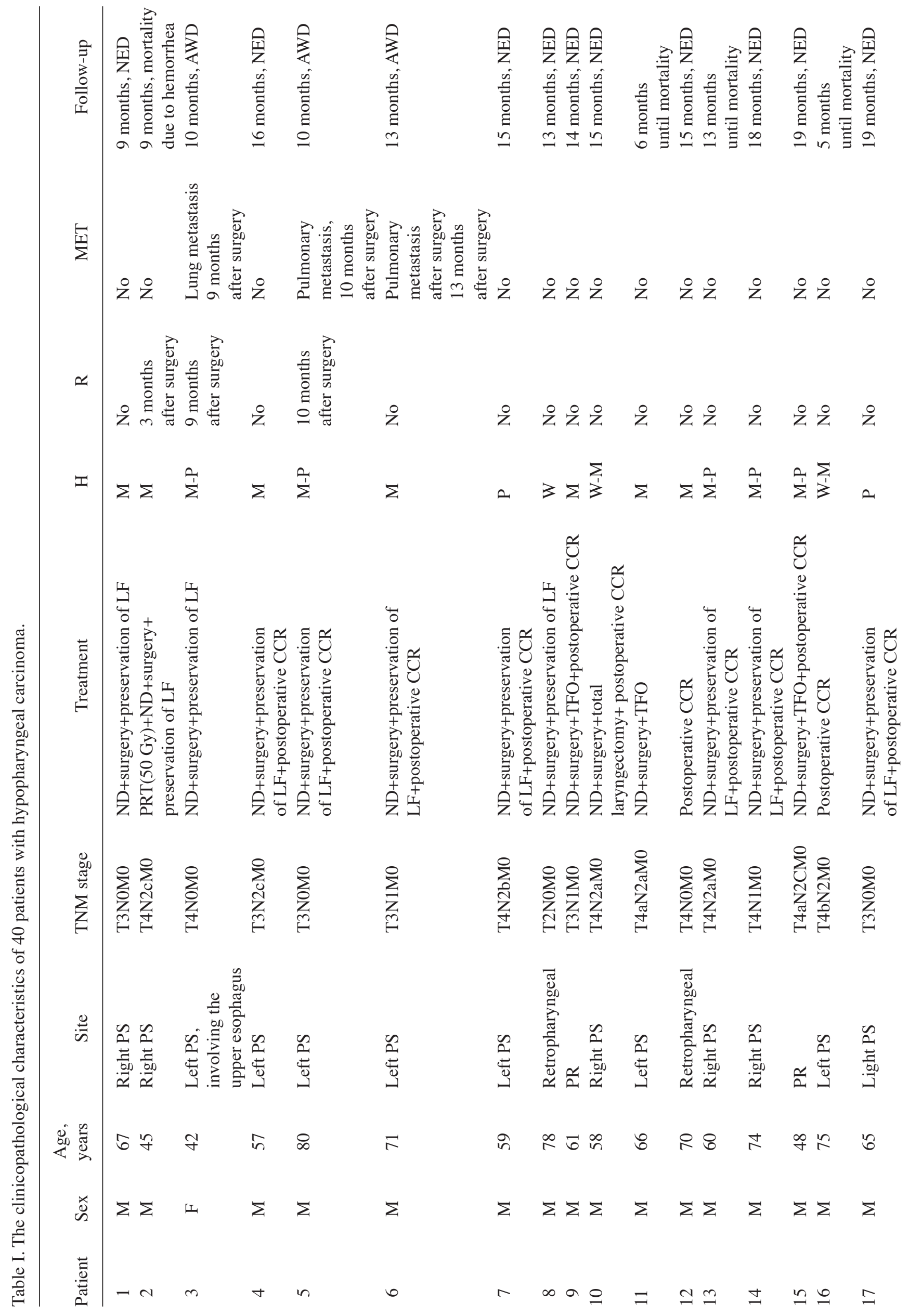




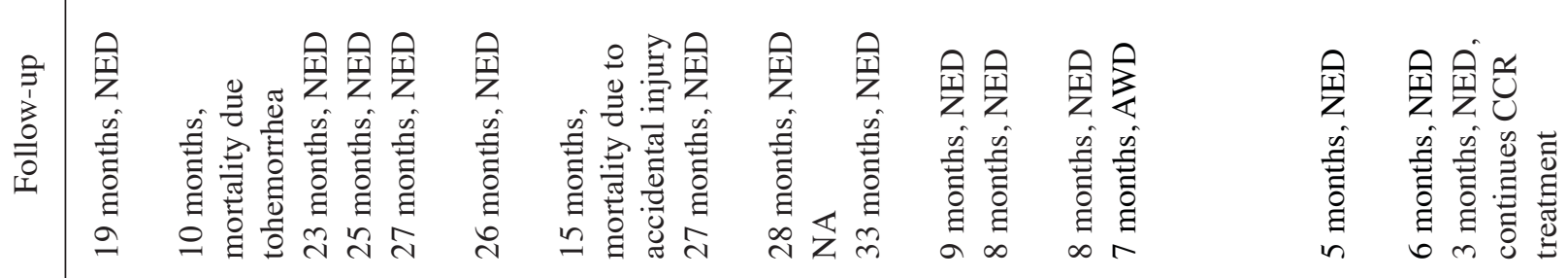

武

之

$\simeq$

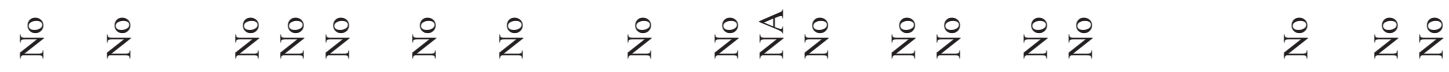

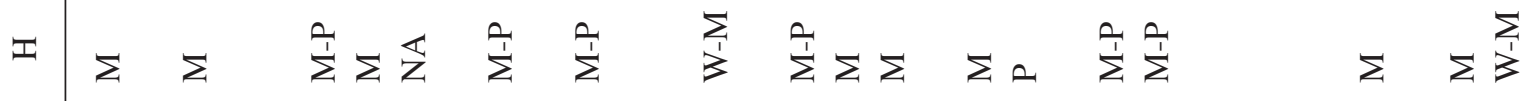

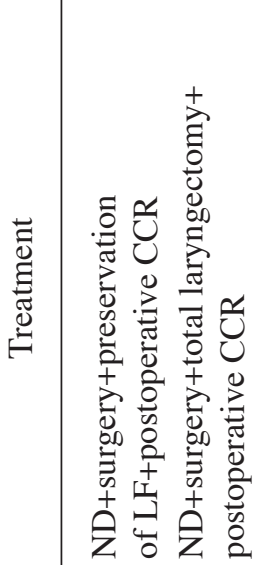

递
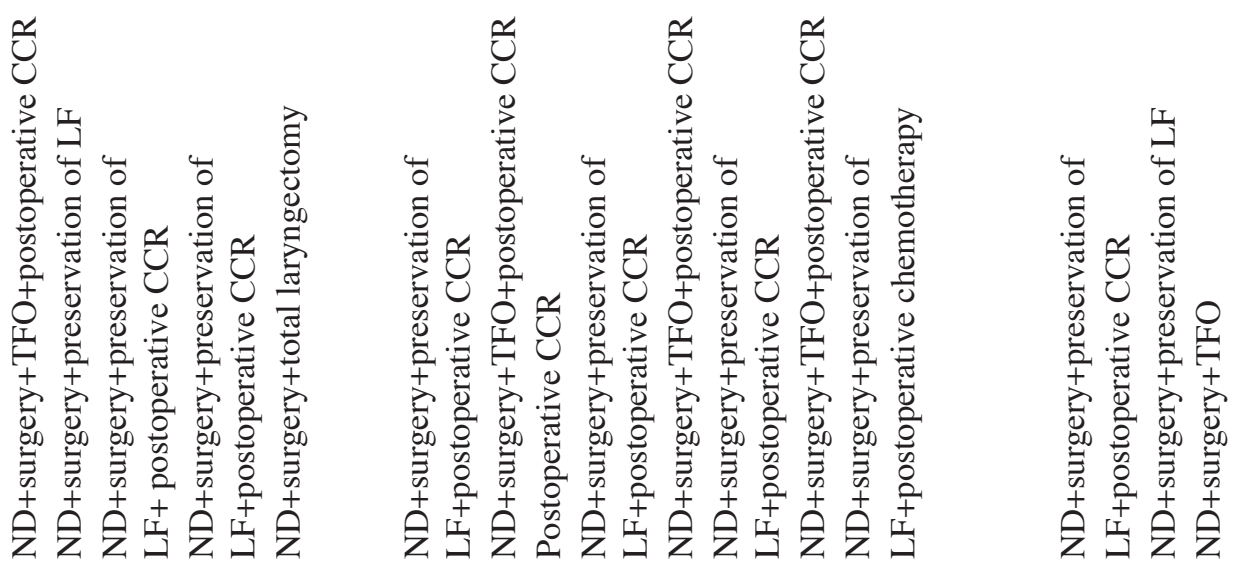

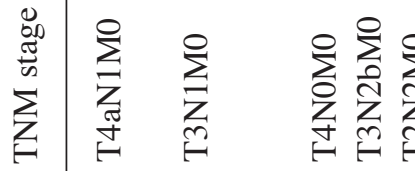

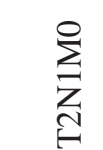

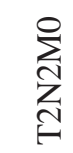

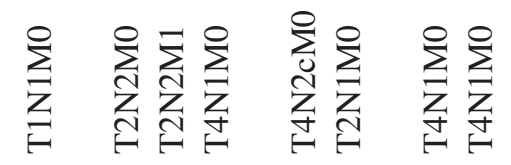

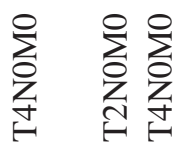

.

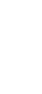

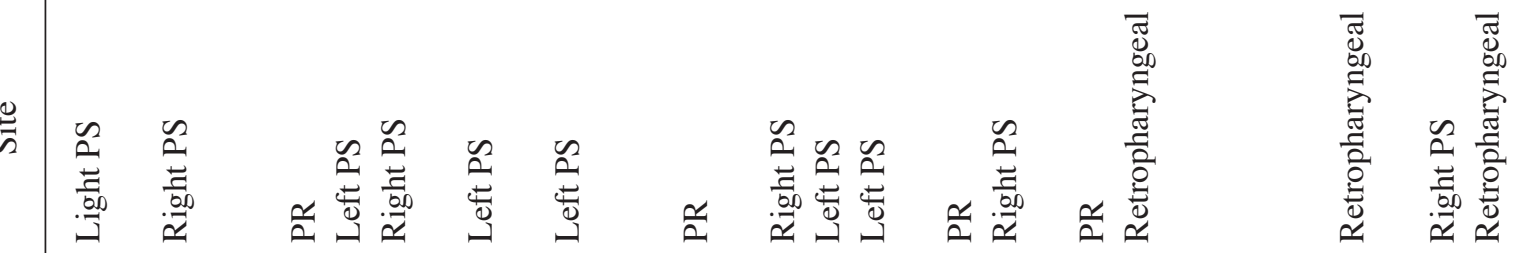

选造

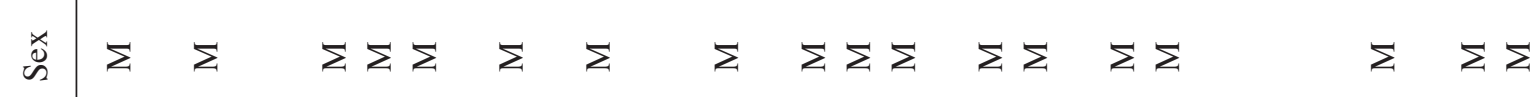

$\stackrel{\overrightarrow{0}}{\stackrel{\vec{*}}{*}}$

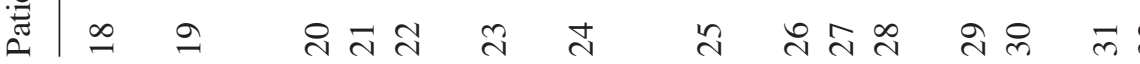

m

m ॠे m 
the native b-1,000 image compared with the surrounding tissue with a corresponding low signal intensity in the matching ADC map was considered positive for a tumor. A high signal intensity on the b-1,000 image with a corresponding high signal intensity on the matching ADC map was considered to represent $\mathrm{T} 2$ shine-through and therefore, the absence of a tumor. The absence of hyper intensity on the b-1,000 image was also considered negative for a tumor. The region of interest (ROI) on single slice was determined by a single radiologist (Department of Radiology (the First Affiliated Hospital, Zhejiang University, Hangzhou, P.R. China) with 20 years of experience. The ROI was determined as previously described (12). In brief, the ROIs were placed on the axial ADC 1,000 maps following referral to contrast-enhanced T1-weighted images obtained in 3 orthogonal planes. The investigator (Department of Radiology (the First Affiliated Hospital, Zhejiang University, Hangzhou, P.R. China) had no knowledge of the final pathological or clinical results when he interpreted the images. The ROIs were drawn on the largest or the highest conspicuity of the lesion of the ADC map. The boundary of the ROI contained the visible tumor in that section of the ADC map corresponding to T1-weighted, T2-weighted, or contrast-enhanced T1-weighted images, but any necrotic portions and normal osseous structures were avoided where possible. The ADC value in the same section was calculated three times. The mean \pm standard deviation (SD) of the ADC values for the hypopharyngeal lesions and cervical lymph nodes were calculated.

Statistical analyses. Statistical analyses were performed using SPSS software 20.0 (IBM Corp., Armonk, NY, USA). $\mathrm{P}<0.05$ was considered to indicate a statistically significant difference. All variables were assessed for normality by using the Kolmogorov-Smirnov test. Spearman's rank correlation was performed to evaluate the correlation between tumor size and ADC value. Differences in ADC (mean \pm SD) of the hypopharyngeal lesions between patients with malignant lesions and those with benign lesions were tested using an independent samples t-test. A 95\% confidence interval was used. In the univariate survival analysis, the curves for overall survival were estimated using the Kaplan-Meier method, and the log rank test was used to test differences between groups. Multivariate analysis was performed using a Cox proportional hazard test.

Receiver operating characteristic (ROC) curve analysis was used to investigate the discriminatory ability of the ADC values in differentiating hypopharyngeal carcinomas from benign lesions. The area under the ROC curve (AUC) was calculated. The ADC value that corresponded to the highest Youden index (sensitivity+specificity-1) was chosen as the optimal ADC threshold value as it optimized the sensitivity and specificity. The AUC was used as an alternative global measure of test performance.

\section{Results}

Patient clinical characteristics. The mean age of the patients with benign hypopharyngeal lesions was 56.5 years (range, 34-74 years). There were 13 males and 2 females. The main symptoms included a sensation of a foreign body in the 
throat and pharyngalgia. The benign hypopharyngeal lesions included 10 cases of chronic inflammation, two vascular lesions, two hypopharyngeal polyps and one cyst.

Of the 40 patients with hypopharyngeal carcinoma, 39 were male and one was female. The mean age was 61.4 years (range, 42-81 years). All 40 hypopharyngeal carcinomas were squamous cell carcinoma (SCC). A total of 29 tumors (72.5\%) were located in the pyriform sinus, $8(20.0 \%)$ were located in the posterior pharyngeal wall and $3(7.5 \%)$ were located in the postcricoid area. A total of 36 patients $(90.0 \%)$ had a history of smoking, $32(80.0 \%)$ had a history of drinking (any alcohol consumption), and $27(67.5 \%)$ had a history of smoking and drinking. Signs and symptoms included odynophagia (32.5\%), difficulty swallowing (30.0\%), sensation of a foreign body in the throat (20.0\%), neck mass $(10.0 \%)$ and hoarseness $(2.5 \%)$. According to the International Union Against Cancer TNM classification system (2007, 7 th edition), 1 patient $(2.5 \%)$ exhibited stage $\mathrm{T}_{1} \mathrm{~N}_{1} \mathrm{M}_{0}$ disease, 3 (7.5\%) exhibited stage $\mathrm{T}_{2} \mathrm{~N}_{0} \mathrm{M}_{0}$ disease, $3(5.0 \%)$ exhibited stage $\mathrm{T}_{2} \mathrm{~N}_{1} \mathrm{M}_{0}$ disease, $3(7.5 \%)$ exhibited stage $\mathrm{T}_{2} \mathrm{~N}_{2} \mathrm{M}_{0}$ disease, $3(7.5 \%)$ exhibited stage $\mathrm{T}_{3} \mathrm{~N}_{0} \mathrm{M}_{0}$ disease, $3(7.5 \%)$ exhibited stage $\mathrm{T}_{3} \mathrm{~N}_{1} \mathrm{M}_{0}$ disease, $4(10.0 \%)$ exhibited stage $\mathrm{T}_{3} \mathrm{~N}_{2} \mathrm{M}_{0}$ disease, 5 (12.5\%) exhibited stage $\mathrm{T}_{4} \mathrm{~N}_{0} \mathrm{M}_{0}$ disease, $6(15.0 \%)$ exhibited stage $\mathrm{T}_{4} \mathrm{~N}_{1} \mathrm{M}_{0}$ disease, 9 (22.5\%) exhibited stage $\mathrm{T}_{4 \mathrm{a}} \mathrm{N}_{2} \mathrm{M}_{0}$ disease, $1(2.5 \%)$ exhibited stage $\mathrm{T}_{2} \mathrm{~N}_{2} \mathrm{M}_{1}$ disease, and one patient developed lung metastasis. With regards to clinical stage (11), 2 patients (5.0\%) exhibited stage II disease, 8 (20.0\%) exhibited stage III disease, and $30(75.0 \%)$ exhibited stage IV disease (Table I). According to current classifications, $95.0 \%$ of patients were at an advanced stage of disease. A total of 3 patients received CCR, while 37 patients received surgery and neck dissection (18 ipsilateral and 19 bilateral). One of the 37 patients received preoperative CCR and 36 received postoperative CCR.

The mean longest diameter of the tumor samples was $4.7 \mathrm{~cm}$ and ranged between 2.0 and $10.0 \mathrm{~cm}$. The mean tumor volume was $38.8 \mathrm{~cm}^{3}$ and ranged between 4.0 and $210 \mathrm{~cm}^{3}$ (Table II).

The mean follow-up time was 12.9 months (range, 1-33 months). A total of 3 patients developed local recurrence and one patient developed lung metastasis. A total of 6 patients succumbed to hypopharyngeal carcinoma, and one mortality occurred as a result of accidental trauma.

Laryngostroboscopy in discriminating hypopharyngeal lesions. Of the 40 patients with hypopharyngeal SCC, 37 were diagnosed with hypopharyngeal carcinoma. Of the 15 patients with hypopharyngeal benign lesions, 3 were diagnosed with hypopharyngeal carcinoma. The sensitivity, specificity and accuracy were $92.5,80.0$ and $89.1 \%$, respectively.

Conventional MRI, DWI, and ADC values: The diagnostic value of conventional MRI in hypopharyngeal lesions. A total of 10/40 hypopharyngeal SCCs $(25.0 \%)$ were hyperintense on the T1-weighted image, $17(42.5 \%)$ were isointense, $11(27.5 \%)$ were hypointense and $2(5.0 \%)$ gave heterogeneous signals. On the T2-weighted images, 38 (95.0\%) were hyperintense, one $(2.5 \%)$ was isointense and one $(2.5 \%)$ gave a heterogeneous signal. In gadopentetic acid contrast-enhanced T1-weighted MRI, 15 (37.5\%) exhibited heterogeneous enhancement, $24(60.0 \%)$ were strongly enhanced and
Table II. Tumor sizes and ADC values.

\begin{tabular}{|c|c|c|c|}
\hline Patient & $\begin{array}{l}\text { Tumordiameter, } \\
\mathrm{cm}\end{array}$ & $\begin{array}{c}\text { Tumor } \\
\text { volume, } \mathrm{cm}^{3}\end{array}$ & $\begin{array}{c}\mathrm{ADC} \\
10^{-3} \mathrm{~mm}^{2} / \mathrm{sec}\end{array}$ \\
\hline 1 & $4.0 \times 3.0 \times 2.50$ & 15.00 & 0.89 \\
\hline 2 & $3.5 \times 3.0 \times 1.0$ & 5.25 & 0.96 \\
\hline 3 & $3.0 \times 3.0 \times 1.2$ & 6.75 & 1.32 \\
\hline 4 & $4 \times 2.5 \times 1.5$ & 7.50 & 0.92 \\
\hline 5 & $3.0 \times 3.0 \times 2.0$ & 9.00 & 1.06 \\
\hline 6 & $3.4 \times 3.0 \times 3.0$ & 15.30 & 1.05 \\
\hline 7 & $4.0 \times 4.0 \times 2.5$ & 20.00 & 0.88 \\
\hline 8 & $5.0 \times 5.0 \times 3.5$ & 43.75 & 1.06 \\
\hline 9 & $7.5 \times 4.5 \times 2$ & 33.75 & 0.92 \\
\hline 10 & $3.0 \times 4.0 \times 4.0$ & 24.00 & 0.70 \\
\hline 11 & $5.0 \times 4.5 \times 1.5$ & 16.88 & 0.80 \\
\hline 12 & $2.0 \times 3.5 \times 3.5$ & 12.25 & 0.97 \\
\hline 13 & $4.0 \times 5.0 \times 5.0$ & 50.00 & 0.45 \\
\hline 14 & $3.0 \times 3.0 \times 3.0$ & 13.50 & 1.05 \\
\hline 15 & $5.0 \times 5.0 \times 5.5$ & 68.75 & 0.98 \\
\hline 16 & $5.0 \times 5.0 \times 5.0$ & 62.50 & 0.80 \\
\hline 17 & $4.0 \times 3.0 \times 3.0$ & 18.00 & 1.41 \\
\hline 18 & $4.0 \times 4.0 \times 5.0$ & 40.00 & 0.97 \\
\hline 19 & $4.0 \times 4.0 \times 5.5$ & 44.00 & 0.96 \\
\hline 20 & $4.0 \times 5.5 \times 5.5$ & 60.50 & 1.00 \\
\hline 21 & $3.0 \times 5.5 \times 7.0$ & 57.75 & 0.89 \\
\hline 22 & $2.0 \times 2.0 \times 2.0$ & 4.00 & 1.14 \\
\hline 23 & $4.0 \times 3.0 \times 3.0$ & 18.00 & 1.16 \\
\hline 24 & $3.0 \times 3.0 \times 3.0$ & 13.50 & 0.88 \\
\hline 25 & $5.0 \times 5.0 \times 4.5$ & 56.25 & 0.90 \\
\hline 26 & $4.0 \times 4.5 \times 4.5$ & 40.50 & 0.91 \\
\hline 27 & $2.0 \times 2.0 \times 2.0$ & 4.00 & 0.91 \\
\hline 28 & $4.0 \times 4.0 \times 4.0$ & 32.00 & 1.24 \\
\hline 29 & $4.0 \times 4.5 \times 4.5$ & 40.50 & 1.07 \\
\hline 30 & $7.3 \times 3.0 \times 2.1$ & 23.00 & 1.04 \\
\hline 31 & $4.0 \times 4.5 \times 5.5$ & 49.50 & 1.66 \\
\hline 32 & $7.0 \times 5.0 \times 5.0$ & 87.50 & 1.06 \\
\hline 33 & $7.0 \times 5.0 \times 5.0$ & 87.50 & 1.34 \\
\hline 34 & $2.0 \times 3.0 \times 3.0$ & 9.00 & 1.07 \\
\hline 35 & $9.0 \times 7.0 \times 5.0$ & 157.50 & 1.09 \\
\hline 36 & $3.0 \times 2.0 \times 2.0$ & 6.00 & 0.95 \\
\hline 37 & $10.0 \times 7.0 \times 6.0$ & 210.00 & 1.07 \\
\hline 38 & $3.0 \times 4.5 \times 4.5$ & 30.38 & 1.18 \\
\hline 39 & $3.0 \times 3.0 \times 3.0$ & 13.50 & 1.37 \\
\hline 40 & $4.0 \times 4.0 \times 5.5$ & 44.00 & 1.06 \\
\hline
\end{tabular}

ADC, apparent diffusion coefficient.

$1(2.5 \%)$ was slightly enhanced. A total of $39 / 40$ pathologically proven hypopharyngeal SCCs were diagnosed as hypopharyngeal carcinoma according to these observations (Table III; sensitivity, 97.5\%).

In the T1-weighted images of 15 benign hypopharyngeal lesions, 3 (20.0\%) exhibited no abnormal signal, 7 (46.7\%) were hypointense, $4(26.7 \%)$ were hyperintense and $1(6.6 \%)$ 
Table III. Conventional MRI observations in 40 hypopharyngeal lesions.

\begin{tabular}{llc}
\hline Sequence & \multicolumn{1}{c}{ Signal } & Patients $(\%)$ \\
\hline T1W & Hyperintense & $10(25.0)$ \\
& Isointense & $17(42.5)$ \\
& Hypointense & $11(27.5)$ \\
& Heterogeneous & $2(5.0)$ \\
T2W & Hyperintense & $38(95.0)$ \\
& Isointense & $1(2.5)$ \\
& Heterogeneous & $1(2.5)$ \\
Contrast-enhanced & & \\
& & $15(37.5)$ \\
& Heterogeneous & $24(60.0)$ \\
& enhancement & $1(2.5)$ \\
\hline
\end{tabular}

T1W, T1-weighted.

was isointense. In the T2-weighted images, 14 (93.3\%) were hyperintense and $1(6.7 \%)$ exhibited no abnormal signal. In the contrast-enhanced T1-weighted MR images, $12(80.0 \%)$ were strongly enhanced and three (20.0\%) exhibited no enhancement. A total of $5 / 15$ pathologically proven benign hypopharyngeal lesions were diagnosed as hypopharyngeal carcinoma. The specificity and accuracy were 66.7 and $89.1 \%$, respectively.

DWI and ADC values. All 40 hypopharyngeal SCCs exhibited a high signal in DWI (Fig. 1). The mean ADC value was $(1.03 \pm 0.0328) \times 10^{-3} \mathrm{~mm}^{2} / \mathrm{sec}$. The ADCs of all patients who succumbed to mortality were below the mean ADC value. The tumor size (diameter and volume) was not significantly correlated with the tumor ADC value $(\mathrm{P}=0.996$ and $\mathrm{P}=0.900$, respectively). A total of 10/15 benign hypopharyngeal lesions (66.7\%) exhibited high signals in DWI (Fig. 2). The mean ADC value $\left(b=1,000 \mathrm{sec} / \mathrm{mm}^{2}\right)$ was $(1.53 \pm 0.106) \times 10^{-3} \mathrm{~mm}^{2} / \mathrm{sec}$. The ADC values of hypopharyngeal SCCs were significantly lower than those of benign lesions $(\mathrm{P}<0.001$; Fig. 3). ROC analysis revealed that the AUC was 0.921, while the optimal threshold for the ADC cut-off point was $1.075 \times 10^{-3} \mathrm{~mm}^{2} / \mathrm{sec}$, resulting in a sensitivity of $100 \%$ and a specificity of $75 \%$ (Fig. 4).

The role of DWI and ADC values in identifying metastatic lymph nodes in hypopharyngeal SCCs. The agreed ADC values in lesions on metastatic cervical lymph nodes and reactive cervical lymph nodes were $0.89 \times 10^{-3} \mathrm{~mm}^{2} / \mathrm{sec}$ and $0.91 \times 10^{-3} \mathrm{~mm}^{2} / \mathrm{sec}$, respectively. Cervical lymph nodes were detected in 38/40 (95.0\%) hypopharyngeal SCCs (Fig. 5). A total of 25 nodes were proven to be histologically malignant and 13 were benign. The mean ADC value of metastatic nodes was $(0.918 \pm 0.0538) \times 10^{-3} \mathrm{~mm}^{2} / \mathrm{sec}$, significantly lower than the mean value of the benign nodes $[1.25 \pm 0.115) \times 10^{-3} \mathrm{~mm}^{2} / \mathrm{sec}$; $\mathrm{t}=3.027 ; \mathrm{P}=0.005)$. $\mathrm{ROC}$ curve analysis revealed that an optimal threshold value of $1.075 \times 10^{-3} \mathrm{~mm}^{2} / \mathrm{sec}$ was suggested as the cut-off point, which results in $69.2 \%$ sensitivity and $84.0 \%$ specificity; the AUC was 0.778 with a confidence interval of 0.619-0.938 ( $\mathrm{P}=0.005$; Fig. 6).

ADC values, $T$ stage and histological grade. The mean ADC value of early stage $\left(\mathrm{T}_{1}+\mathrm{T}_{2}\right)$ hypopharyngeal SCCs was $(0.998 \pm 0.0367) \times 10^{-3} \mathrm{~mm}^{2} / \mathrm{sec}$. The mean ADC value of advanced stage $\left(\mathrm{T}_{3}+\mathrm{T}_{4}\right)$ hypopharyngeal SCCs was $(1.04 \pm 0.0412) \times 10^{-3} \mathrm{~mm}^{2} / \mathrm{sec}$. However, this difference was not statistically significant $(\mathrm{P}>0.05)$. The mean ADC values of cases that were well differentiated, moderately differentiated, and poorly differentiated were $(0.955 \pm 0.0590) \times 10^{-3} \mathrm{~mm}^{2} / \mathrm{sec}$, $(1.01 \pm 0.0337) \times 10^{-3} \mathrm{~mm}^{2} / \mathrm{sec}$ and $(1.08 \pm 0.0686) \times 10^{-3} \mathrm{~mm}^{2} / \mathrm{sec}$, respectively. However, these differences were not statistically significant $(\mathrm{P}>0.05)$.

Prognosis and ADC values. Cases were divided into two groups according to the mean ADC values of hypopharyngeal SCCs $\left[\leq(1.03 \pm 0.0328) \times 10^{-3} \mathrm{~mm}^{2} / \mathrm{sec}\right.$ vs. $>(1.03 \pm 0.0328)$ $\mathrm{x} 10^{-3} \mathrm{~mm}^{2} / \mathrm{sec}$ ). The 2 -year overall survival rates of the groups were 55.6 and $100.0 \%$, respectively, a statistically significant difference (Fig. $7 ; \chi^{2}=5.073 ; \mathrm{P}<0.02$ ). According to univariate analysis, other clinical parameters including age, sex, site of tumor, $\mathrm{T}$ stage, $\mathrm{N}$ stage and distant metastasis were not significant prognostic factors for survivalin hypopharyngeal carcinoma $(\mathrm{P}>0.05)$. However, recurrence and treatment modalities were prognostic factors for survival in hypopharyngeal carcinoma $(\mathrm{P}=0.016$ and $\mathrm{P}<0.001$, respectively). Patients who received surgical treatment in addition to postoperative CCR exhibited a better survival rate than those who received these treatment modalities alone. However, multivariate analysis indicated that recurrence was the only independent risk factor for survival in hypopharyngeal carcinoma $(\mathrm{P}<0.05)$.

\section{Discussion}

DWI has been widely used in the diagnosis, differential diagnosis and evaluation of cancer differentiation, clinical stage, outcome, recurrence and metastasis (9-14). Head and neck cancer occurs at multiple sites, including the oral cavity, oropharynx and larynx $(9,10)$. In our previous study, ADC values were revealed to be lower in patients with $T_{1}$ and $T_{2}$ laryngeal carcinoma [mean, $(1.195 \pm 0.32) \times 10^{-3} \mathrm{~mm}^{2} / \mathrm{sec}$ ] than in those with laryngeal precancerous lesions [mean, $(1.780 \pm 0.32)$ $\left.\mathrm{x} 10^{-3} \mathrm{~mm}^{2} / \mathrm{sec} ; \mathrm{P}<0.001\right]$ (12). ROC analysis revealed that the optimum threshold for the ADC was $1.455 \times 10^{-3} \mathrm{~mm}^{2} / \mathrm{sec}$, which may aid in distinguishing laryngeal carcinomas from laryngeal precancerous lesions (12). The present study continued to investigate the value of DWI in the diagnosis of hypopharyngeal carcinoma and in predicting its prognosis.

The results of the present study revealed that all 40 hypopharyngeal SCCs exhibited a high signal intensity in DWI. Furthermore, the mean ADC value of hypopharyngeal SCCs was lower than that of benign lesions $(\mathrm{P}<0.001)$.

These observations were similar to those from our previous study on early laryngeal carcinoma (12) and to those of other previous studies on head and neck carcinomas $(4,10,15)$. Li et al (15) revealed that the mean ADC value of malignant 

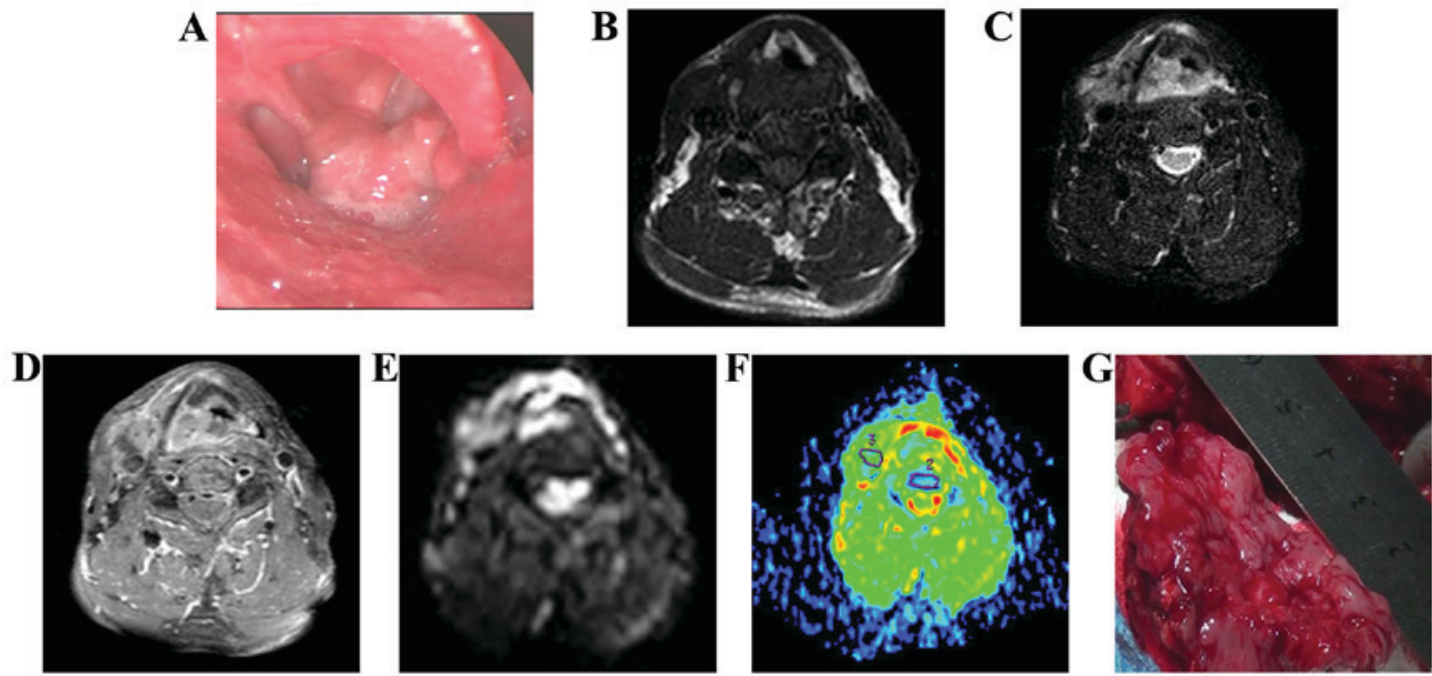

Figure 1. Laryngostroboscopy, MRI, DWI and surgical sections from a patient with hypopharyngeal carcinoma. (A) Laryngostroboscopy indicated a mass in the right pyriform sinus. (B) T1-weighted imaging revealed hypointensityon axial scanning. (C) T2-weighted imaging demonstrated hyperintensity on axial scanning. (D) Contrast-enhanced T1-weighted MRI indicated strong enhancement on axial scanning. (E) DWI suggested hyperintense lesions in the right pyriform sinus $\left(\mathrm{b}=1,000 \mathrm{sec} / \mathrm{mm}^{2}\right)$. (F) The apparent diffusion coefficient value was $0.447 \times 10^{-3} \mathrm{~mm}^{2} / \mathrm{sec}$. (G) Surgical section. The tumor diameter was $\sim 4.0 \times 5.0 \mathrm{~cm}$. MRI, magnetic resonance imaging; DWI, diffusion-weighted magnetic resonance imaging.
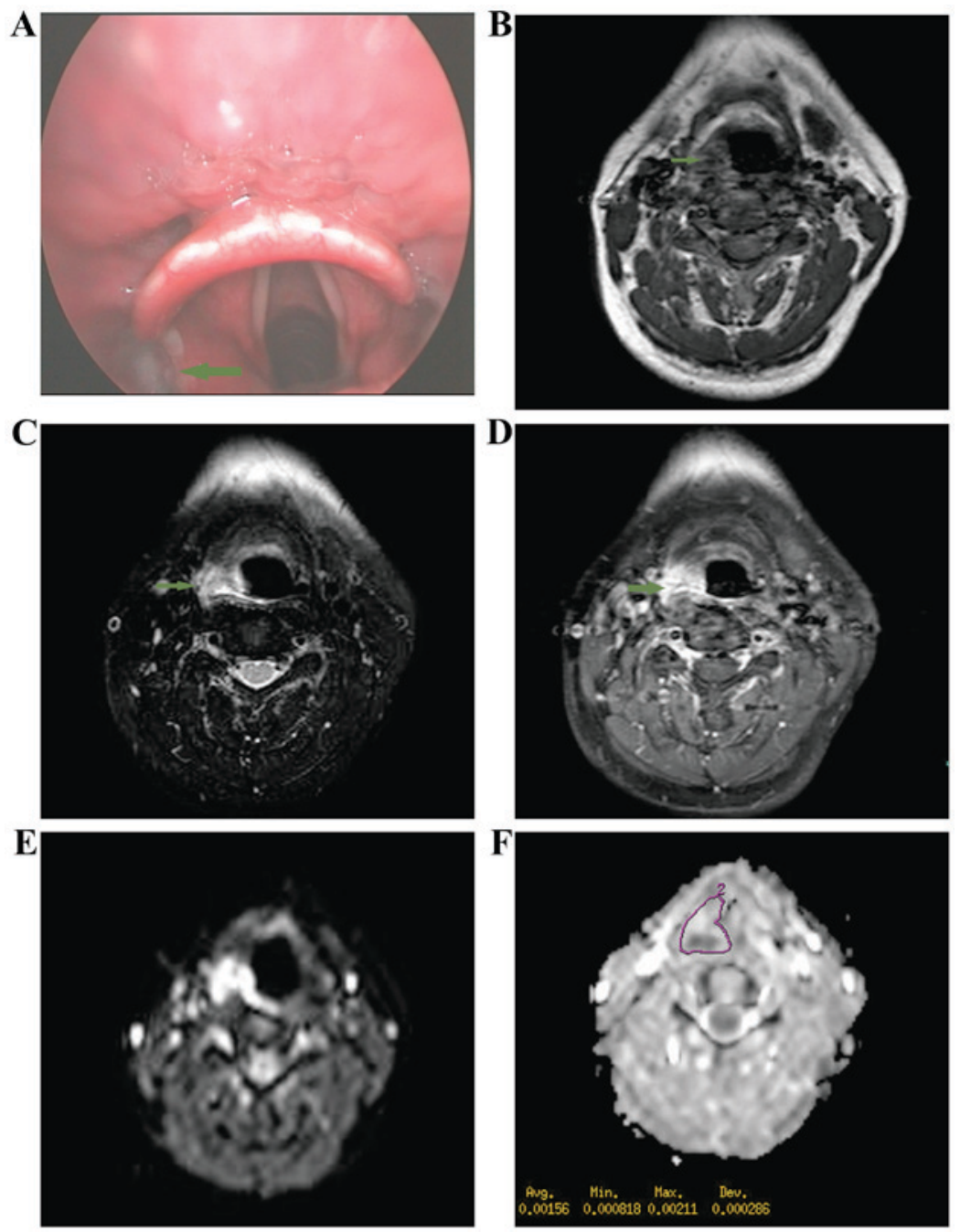

Figure 2. Laryngostroboscopy, MRI and DWI from a patient with a hypopharyngeal ulcer. (A) Laryngostroboscopy indicated an ulcer in the right pyriform sinus. (B) T1-weighted imaging revealed hypointensity on axial scanning. (C) T2-weighted imaging demonstrated hyperintensity on axial scanning. (D) Contrast-enhanced T1-weighted MRI indicated strong enhancement on axial scanning. (E) DWI suggested hyperintense lesions in the right pyriform sinus $\left(\mathrm{b}=1,000 \mathrm{sec} / \mathrm{mm}^{2}\right)$. (F) The apparent diffusion coefficient value was $1.56 \times 10^{-3} \mathrm{~mm}^{2} / \mathrm{sec}$. MRI, magnetic resonance imaging; DWI, diffusion-weighted magnetic resonance imaging. 


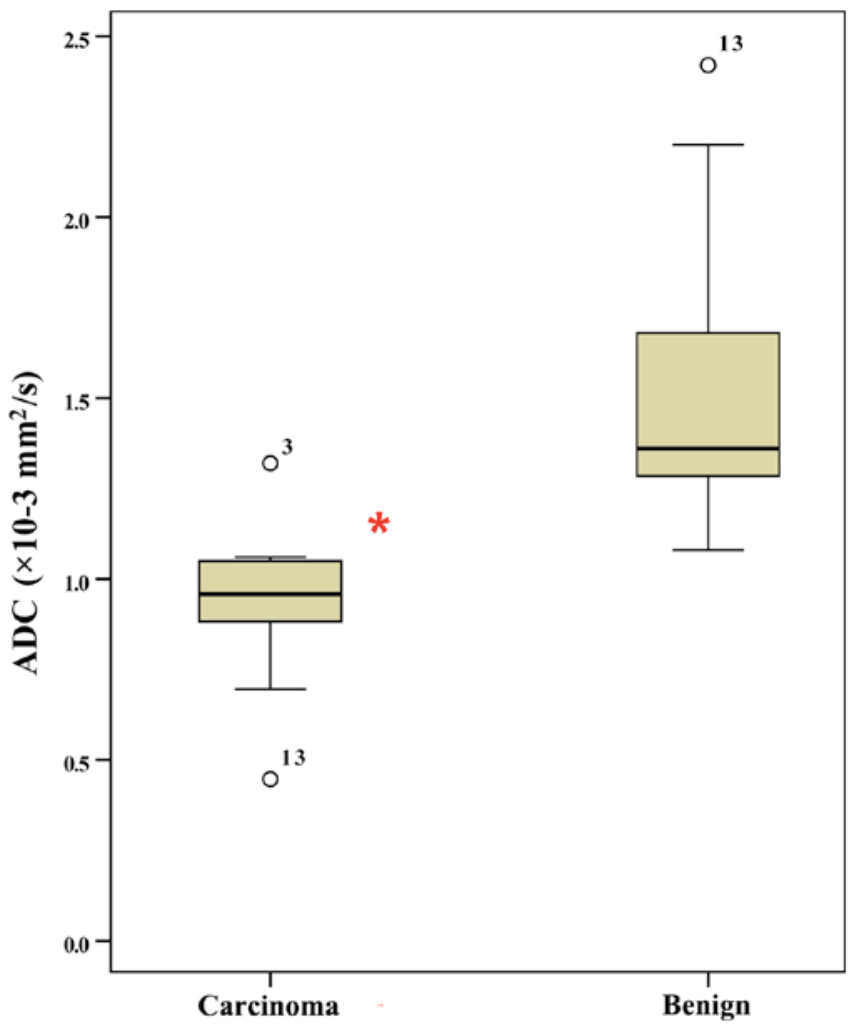

Figure 3. Box and whisker plots demonstrating ADC values for hypopharyngeal carcinomas and hypopharyngeal benign lesions. ADC values were lower in patients with hypopharyngeal carcinoma [mean, $(1.03 \pm 0.0328)$ $\left.\mathrm{x} 10^{-3} \mathrm{~mm}^{2} / \mathrm{sec}\right]$ than in patients with hypopharyngeal benign lesions $\left[(1.53 \pm 0.106) \times 10^{-3} \mathrm{~mm}^{2} / \mathrm{sec} ;{ }^{*} \mathrm{P}<0.001\right)$. Horizontal line, median values; bottom of the box, 25th percentile; top of the box, 75th percentile; whiskers, smallest and largest values excluding outliers; small circle, outliers. ADC, apparent diffusion coefficient.

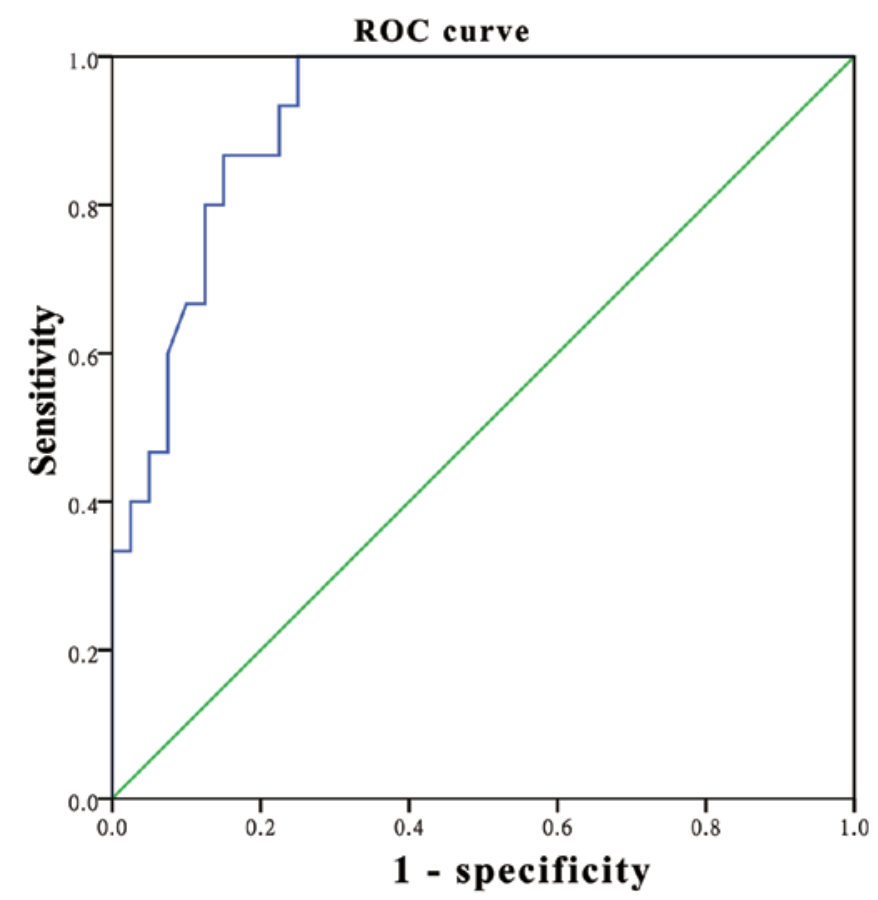

Figure 4. ROC curve analysis of hypopharyngeal carcinomas and hypopharyngeal benign lesions revealed that the area under the curve was 0.921 while the optimal threshold for the apparent diffusion coefficient cut-off point was $1.075 \times 10^{-3} \mathrm{~mm}^{2} / \mathrm{sec}$, resulting in a sensitivity of $100 \%$ and a specificity of $75 \%$. ROC, receiver operating characteristic.
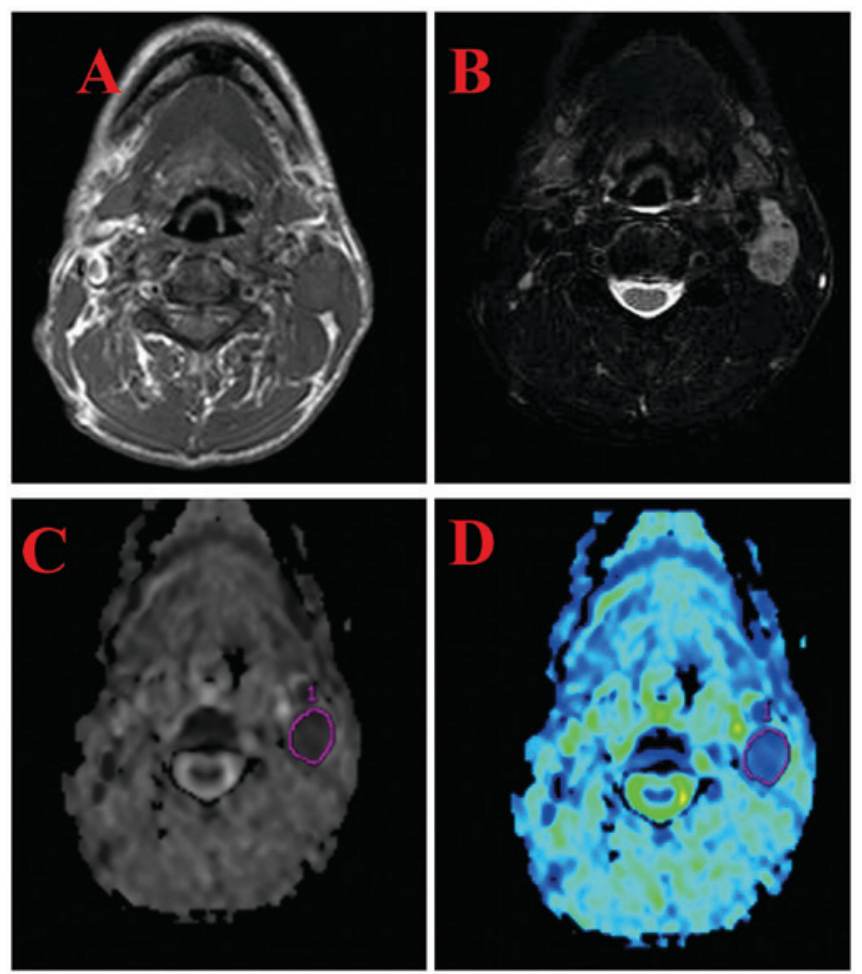

Figure 5. MRI and DWI in a patient with metastatic cervical lymph nodes of hypopharyngeal carcinoma. (A) T1-weighted imaging on axial scanning revealed hypointensity. (B) T2-weighted imaging on axial scanning demonstrated hyperintensity. (C) DWI indicated hyperintense lesions in the left cervical lymph node $\left(b=1,000 \mathrm{sec} / \mathrm{mm}^{2}\right)$. (D) The apparent diffusion coefficient value was $0.904 \times 10^{-3} \mathrm{~mm}^{2} / \mathrm{s}$. MRI, magnetic resonance imaging; DWI, diffusion-weighted magnetic resonance imaging.

lesions of the tongue $\left[(1.08 \pm 0.16) \times 10^{-3} \mathrm{~mm}^{2} / \mathrm{sec}\right]$ was lower than that of benign lesions $\left[(1.68 \pm 0.33) \times 10^{-3} \mathrm{~mm}^{2} / \mathrm{sec}\right]$ and cystic lesions $\left[(2.21 \pm 0.35) \times 10^{-3} \mathrm{~mm}^{2} / \mathrm{sec} ; \mathrm{P}<0.001\right]$. ROC analysis revealed that the AUC was 0.963 and the optimal threshold for the ADC cut-off point was $1.31 \times 10^{-3} \mathrm{~mm}^{2} / \mathrm{sec}$ for predicting malignancy (15). A meta-analysis investigating DWI as a tool for differentiating malignancy from benign thyroid nodules undertaken by $\mathrm{Wu}$ et al (9) revealed that DWI sensitivity was 0.91 (95\% CI, 0.86-0.94), specificity was 0.92 (95\% CI, 0.84-0.97), and ROC curves demonstrated that AUC was 0.94 (95\% CI, 0.92-0.96), indicating a high level of overall accuracy. A systemic review by Driessen et al (10) demonstrated that the accuracy range of DWI was $66-86 \%$ in the detection of primary head and neck squamous cell carcinoma (HNSCC). The mean of the ADC values in malignant lesions was significantly lower than that in benign lesions (4). This may be due to increased cell density, which restricts diffusion thereby decreasing ADC values in malignant lesions $(4,6)$. Driessen et al (10) investigated the association between the ADC values of laryngeal and hypopharyngeal carcinomas and histopathological observations. A significant inverse correlation was observed between ADC values and cell density, nuclear area and the nuclear-cytoplasmic ratio, and a positive correlation was observed between ADC values and percentage area of the stroma (10). However, there is no standard ADC value that may be used as an optimal threshold for differentiating malignant lesions from benign lesions in the head and neck region $(4,6,10,12)$. The wide variation in ADC 

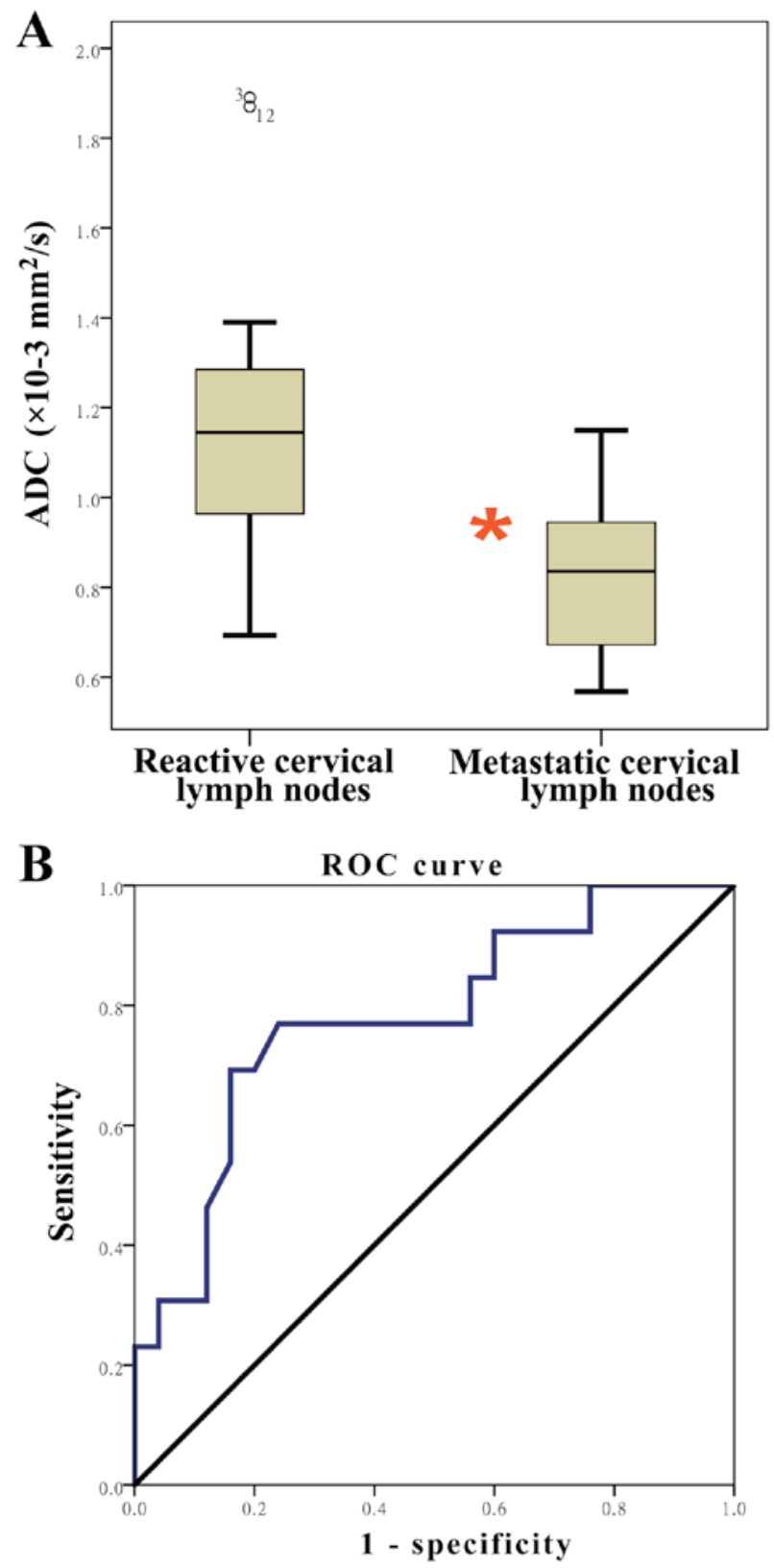

Figure 6. (A) Box and whisker plots demonstrating the ADC values of metastatic cervical lymph nodes and reactive cervical lymph nodes. ADC values were lower in patients with hypopharyngeal carcinoma [mean, $(0.918 \pm 0.0538)$ $\mathrm{x} 10^{-3} \mathrm{~mm}^{2} / \mathrm{sec}$ compared with those with hypopharyngeal benign lesions [(1.25 \pm 0.115$\left.) \times 10^{-3} \mathrm{~mm}^{2} / \mathrm{sec} ;{ }^{*} \mathrm{P}=0.005\right]$. Horizontal line, median values; bottom of the box, 25th percentile; top of the box, 75th percentile; whiskers, smallest and largest values excluding outliers; small circle, outliers. (B) ROC curve analysis of metastatic cervical lymph nodes and reactive cervical lymph nodes revealed that an optimal threshold value of $1.075 \times 10^{-3} \mathrm{~mm}^{2} / \mathrm{sec}$ was suggested as the cut-off point, resulting in $69.2 \%$ sensitivity and $84.0 \%$ specificity. The area under the curve was 0.778 with a confidence interval of 0.619-0.938 (" $\mathrm{P}=0.005)$. ADC, apparent diffusion coefficient; ROC, receiver operating characteristic.

thresholds may be due to multiple factors, including different b-values, field strengths, pathological types and delineation methods $(4,6)$.

The present study revealed that ADC values were not correlated with tumor size. This observation was similar to that of McVeigh et al (16), who observed no correlation between ADC values and tumor volumes in cervical cancer. However,

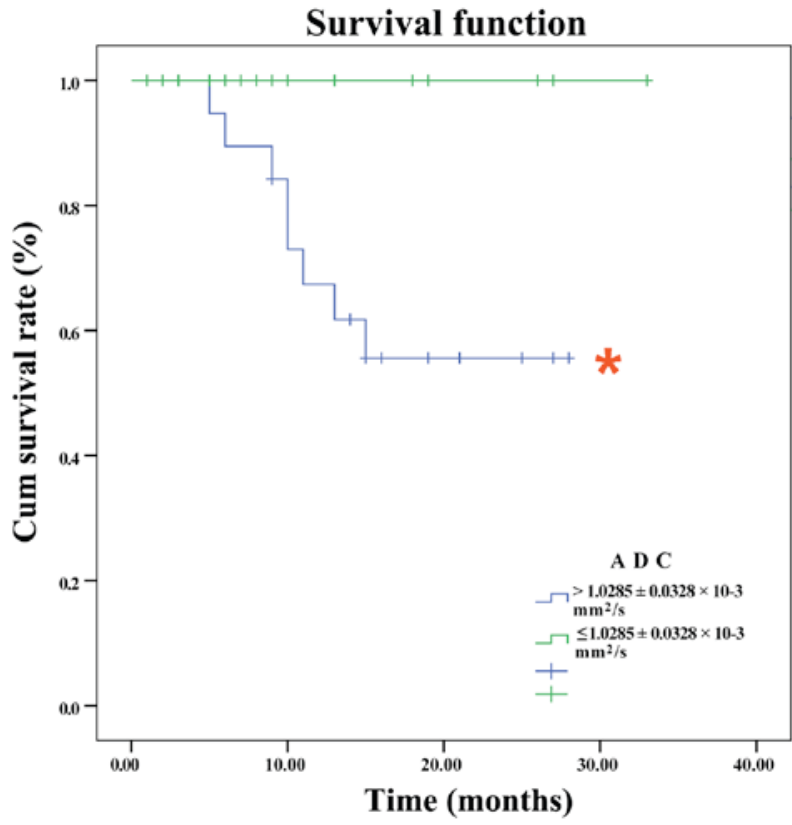

Figure 7. Patients were separated into two groups according to the mean of the ADC value of the hypopharyngeal carcinoma $\left[\leq(1.0285 \pm 0.0328) \times 10^{-3} \mathrm{~mm}^{2} / \mathrm{sec}\right.$ vs. $\left.>(1.0285 \pm 0.0328) \times 10^{-3} \mathrm{~mm}^{2} / \mathrm{sec}\right]$. The 2 -year survival rates of the two groups were 55.6 and $100.0 \%$, respectively. This difference was statistically significant $\left(\chi^{2}=5.073 ;{ }^{*} \mathrm{P}=0.024\right)$. ADC, apparent diffusion coefficient.

Husby et al (17) observed that ADC values were negatively correlated with tumor volume in endometrial carcinomas, suggesting that tumor volume reflects tumor progression and prognosis in endometrial carcinoma. The difference in the aforementioned results may be due to the various measurement methods used and the different $b$-values.

Another important feature of DWI is that ADC values may aid in detecting metastatic lymph nodes in patients with $\operatorname{HNSCC}(3,4,18,19)$. In the present study, 25 cervical lymph nodes were proven to be histologically malignant and 13 nodes were benign. The mean ADC value of metastatic nodes was significantly lower than that of benign nodes $(\mathrm{P}=0.005)$. ROC curve analysis revealed that an optimal threshold value of $1.075 \times 10^{-3} \mathrm{~mm}^{2} / \mathrm{sec}$ was recommended as the cut-off point, resulting in $69.2 \%$ sensitivity and $84.0 \%$ specificity; the AUC was 0.778 (95\% CI, 0.619-0.938; $\mathrm{P}=0.005)$. Additionally, Pekçevik et al (18) analyzed 33 patients with 53 metastatic lymph nodes of HNSCC. The mean ADC values for nodal metastases of nasopharyngeal carcinomas were significantly lower than those for nodal metastases of laryngeal carcinomas. Zhong et al (3) observed that 48 nodes were proven to be histologically malignant in 30 patients with HNSCC and 17 nodes were benign. The mean ADC value of the metastatic nodes $\left(0.849 \times 10^{-3} \mathrm{~mm}^{2} / \mathrm{sec}\right)$ was significantly lower than that of the benign nodes $\left(1.443 \times 10^{-3} \mathrm{~mm}^{2} / \mathrm{sec} ; \mathrm{P}<0.05\right)$. ROC curve analysis revealed that the AUC was 0.83 and the optimal threshold value was $0.960 \times 10^{-3} \mathrm{~mm}^{2} / \mathrm{sec}$, resulting in $89.58 \%$ sensitivity, $76.47 \%$ specificity and $86.15 \%$ accuracy. The aforementioned study also revealed that DWI with ADC value measurements may be more accurate than $\mathrm{CT}$ perfusion for the preoperative diagnosis of cervical lymph node metastases in patients with HNSCC (3). In oral squamous cell carcinoma (OSCC), 21 nodes were proven to be histologically malignant 
in 25 patients with OSCC and 30 nodes were reactive (18). The mean ADC value of the metastatic nodes $[(0.702 \pm 0.197)$ $\mathrm{x} 10^{-3} \mathrm{~mm}^{2} / \mathrm{sec}$ ] was lower than that of the benign nodes $\left[(1.037 \pm 0.149) \times 10^{-3} \mathrm{~mm}^{2} / \mathrm{sec} ; \mathrm{P}<0.05\right)$. ROC curve analysis revealed that the AUC was 0.887 and the optimal threshold value was $0.887 \times 10^{-3} \mathrm{~mm}^{2} / \mathrm{sec}$, resulting in $93.33 \%$ sensitivity, $80.95 \%$ specificity and $88.20 \%$ accuracy (18). However, Lim et al (20) revealed that the mean ADC does not discriminate benign from metastatic cervical lymph nodes in patients with HNSCC and non-necrotic, small lymph nodes. The aforementioned study also suggested that metastatic small foci in lymph nodes did not create sufficient architectural change to affect ADC values. However, the patients included in the study were examined using different MRI scanners (1.5-T, 3-T) (20). Sumi et al (21) observed the opposite results to those of the present study; higher ADC values in metastatic nodes than in benign lymphadenopathy (21). This discrepancy may be due to the number of necrotic regions within the metastatic nodes (21). Taken together, these data suggest that further large-scale studies focused on discriminating benign from metastatic cervical lymph nodes using ADC values are required.

In the present study, univariate analysis revealed that the mean ADC value was associated with the prognosis of patients with hypopharyngeal carcinoma. However, no significant correlation was observed between the mean ADC value and the prognosis of patients with hypopharyngeal carcinoma according to multivariate analysis, and the only independent risk factor for survival was recurrence. Similarly, in other types of cancer, Zhang et al (14) revealed that high ADC values were a good prognostic indicator in 541 patients with nasopharyngeal carcinoma (14). Hatakenaka et al (22) revealed found that $\mathrm{ADC}$ values were an independent prognostic indicator in cases of HNSCC treated with radiotherapy. Yoshida et al (23) also revealed that low ADC values $\left(<1.10 \times 10^{-3} \mathrm{~mm}^{2} / \mathrm{sec}\right)$ were significantly associated with shorter cancer-specific survival of patients with upper urinary tract cancer. However, certain studies have reported that ADC values were not associated with survival of patients with HNSCC who were treated with radiotherapy $(24,25)$. The reason for these contradictory results remains unclear. Hatakenaka et al (22) assessed possible reasons and proposed that ADC values calculated from different b-values may have an effect. For example, ADC values of 0 and $1,000 \mathrm{sec} / \mathrm{mm}^{2}$ are not significantly associated with overall survival in patients with HNSCC treated with radiotherapy. In the aforementioned study, patients with a higher ADC value $\left(0-200 \mathrm{sec} / \mathrm{mm}^{2}\right)$ exhibited a relatively good prognosis, while those with a lower ADC value (300-1,000 sec/ $\mathrm{mm}^{2}$ ) exhibited a favorable prognosis (22). It was suggested that the spatial distribution of photons in cancer cells is heterogeneous; certain cancer cells with low ADC values were critically damaged following radiotherapy, while other adjacent cells were not (22). These critically damaged cells prevented chemical substances from diffusing to adjacent cancer cells and resulted in damage to the adjacent cancer cells and radio sensitivity. There may also be a converse effect in those cancer cells with high ADC values (22). The present study revealed that ADC values were not associated with $\mathrm{T}$ stage or histological grade, observations with were similar to those of previous reports $(23,26)$. Recently, it has been suggested that a histogram of ADC values may better reflect $\mathrm{ADC}$ heterogeneity. Certain studies have demonstrated that ADC histograms may be associated with $\mathrm{T}$ stage and prognosis of certain types of solid cancer (27-29). Therefore, future studies should investigate the association between ADC histograms and prognosis in HNSCC.

The present study has certain limitations. To begin with, the present study incorporated a small sample size with relatively short follow-up periods. Additionally, only advanced-stage hypopharyngeal carcinoma was investigated. Furthermore, multiple b-values were not used to calculate ADCs. Finally, the present study was retrospective in nature, resulting in unavoidable bias. Therefore, large-scale prospective multi-center studies are required for further study.

In conclusion, ADC values may discriminate hypopharyngeal carcinomas from benign lesions and may also discriminate metastatic lymph nodes of hypopharyngeal SCCs from reactive cervical lymph nodes. Furthermore, mean ADC values may be a useful prognostic factor in univariate analysis.

\section{Acknowledgements}

The present study was supported by the National Natural Science Foundation of China (grant no. 81372903) and the Science and Technology Department of Zhejiang Province, China (grant no. 2016C33G2010117).

\section{Competing interests}

The authors declare that they have no competing interests.

\section{References}

1. Kim JW, Kim MS, Kim SH, Kim JH, Lee CG, Kim GE and Keum KC: Definitive chemoradiotherapy versus surgery followed by adjuvant radiotherapy in resectable stage III/IV hypopharyngeal cancer. Cancer Res Treat 48: 45-53, 2016.

2. Vandersteen C, Benezery K, Chamorey E, Ettaiche M, Dassonville O, Poissonnet G, Riss JC, Pierre CS, Hannoun-Lévi JM, Chand Me, et al: Contemporary therapeutic management of locally advanced hypopharyngeal cancer: oncologic and functional outcomes-a report on 100 cases. Acta Otolaryngol 135: 193-200, 2015.

3. Zhong J, Lu Z, Xu L, Dong L, Qiao H, Hua R, Gong Y, Liu Z, Hao C, Liu X, et al: The diagnostic value of cervical lymph node metastasis in head and neck squamous carcinoma by using diffusion-weighted magnetic resonance imaging and computed tomography perfusion. Biomed Res Int 2014: 260859, 2014.

4. Driessen JP, van Kempen PM, van der Heijden GJ, Philippens ME, Pameijer FA, Stegeman I, Terhaard CH, Janssen LM and Grolman W: Diffusion-weighted imaging in head and neck squamous cell carcinomas: A systematic review. Head Neck 37: 440-448, 2015.

5. Sun Y, Tong T, Cai S, Bi R, Xin C and Gu Y: Apparent diffusion coefficient (ADC) value: A potential imaging biomarker that reflects the biological features of rectal cancer. PLoS One 9: e109371, 2014.

6. Payne KF, Haq J, Brown J and Connor S: The role of diffusion-weighted magnetic resonance imaging in the diagnosis, lymph node staging and assessment of treatment response of head and neck cancer. Int J Oral Maxillofac Surg 44: 1-7, 2015.

7. Chawla S, Kim S, Wang S and Poptani H: Diffusion-weighted imaging in head and neck cancers. Future Oncol 5: 959-975, 2009.

8. Thoeny HC, De Keyzer F and King AD: Diffusion-weighted MR imaging in the head and neck. Radiology 263: 19-32, 2012.

9. Wu LM, Xu JR, Liu MJ, Zhang XF, Hua J, Zheng J and Hu JN: Value of magnetic resonance imaging for nodal staging in patients with head and neck squamous cell carcinoma: A meta-analysis. Acad Radiol 19: 331-340, 2012. 
10. Driessen JP, Caldas-Magalhaes J, Janssen LM, Pameijer FA, Kooij N, Terhaard CH, Grolman W and Philippens ME: Diffusion-weighted MR imaging in laryngeal and hypopharyngeal carcinoma: Association between apparent diffusion coefficient and histologic findings. Radiology 272: 456-463, 2014.

11. Lee CC, Ho HC, Su YC, Yu CH and Yang CC: Modified tumor classification with inclusion of tumor characteristics improves discrimination and prediction accuracy in oral and hypopharyngeal cancer patients who underwent surgery. Medicine (Baltimore) 94: e1114, 2015.

12. Shang DS, Ruan LX, Zhou SH, Bao YY, Cheng KJ and Wang QY: Differentiating laryngeal carcinomas from precursor lesions by diffusion-weighted magnetic resonance imaging at $3.0 \mathrm{~T}$ : A preliminary study. PLoS One 8: e68622, 2013.

13. Hwang I, Choi SH, Kim YJ, Kim KG, Lee AL, Yun TJ, Kim JH and Sohn CH: Differentiation of recurrent tumor and posttreatment changes in head and neck squamous cell carcinoma: Application of high $b$-value diffusion-weighted imaging. AJNR Am J Neuroradiol 34: 2343-2348, 2013.

14. Zhang Y, Liu X, Zhang Y, Li WF, Chen L, Mao YP, Shen JX, Zhang F, Peng H, Liu Q, et al: Prognostic value of the primary lesion apparent diffusion coefficient (ADC) in nasopharyngeal carcinoma: A retrospective study of 541 cases. Sci Rep 5: 12242 , 2015.

15. Li S, Cheng J, Zhang Y and Zhang Z: Differentiation of benign and malignant lesions of the tongue by using diffusion-weighted MRI at 3.0 T. Dentomaxillofac Radiol 44: 20140325, 2015.

16. McVeigh PZ, Syed AM, Milosevic M, Fyles A and Haider MA Diffusion-weighted MRI in cervical cancer. Eur Radiol 18: 1058-1064, 2008.

17. Husby JA, Salvesen $\varnothing \mathrm{O}$, Magnussen IJ, Trovik J, Bjørge L, Salvesen HB and Haldorsen IS: Tumour apparent diffusion coefficient is associated with depth of myometrial invasion and is negatively correlated to tumour volume in endometrial carcinomas. Clin Radiol 70: 487-494, 2015.

18. Pekçevik Y, Çukurova İ and Arslan İB: Apparent diffusion coefficient for discriminating metastatic lymph nodes in patients with squamous cell carcinoma of the head and neck. Diagn Interv Radiol 21: 397-402, 2015

19. Si J, Huang S, Shi H, Liu Z, Hu Q, Wang G, Shen G and Zhang D: Usefulness of 3T diffusion-weighted MRI for discrimination of reactive and metastatic cervical lymph nodes in patients with oral squamous cell carcinoma: A pilot study. Dentomaxillofac Radiol 43: 20130202, 2014

20. Lim HK, Lee JH, Baek HJ, Kim N, Lee H, Park JW, Kim SY, Cho KJ and Baek JH: Is diffusion-weighted MRI useful for differentiation of small non-necrotic cervical lymph nodes in patients with head and neck malignancies? Korean J Radiol 15: 810-816, 2014

21. Sumi M, Sakihama N, Sumi T, Morikawa M, Uetani M, Kabasawa H, Shigeno K, Hayashi K, Takahashi $\mathrm{H}$ and Nakamura T: Discrimination of metastatic cervical lymph nodes with diffusion-weighted MR imaging in patients with head and neck cancer. AJNR Am J Neuroradiol 24: 1627-1634, 2003.
22. Hatakenaka M, Nakamura K, Yabuuchi H, Shioyama Y, Matsuo Y, Kamitani T, Yonezawa M, Yoshiura T, Nakashima T, Mori $\mathrm{M}$ and Honda $\mathrm{H}$ : Apparent diffusion coefficient is a prognostic factor of head and neck squamous cell carcinoma treated with radiotherapy. Jpn J Radiol 32: 80-89, 2014.

23. Yoshida S, Kobayashi S, Koga F, Ishioka J, Ishii C, Tanaka H, Nakanishi Y, Matsuoka Y, Numao N, Saito K, et al: Apparent diffusion coefficient as a prognostic biomarker of upper urinary tract cancer: A preliminary report. Eur Radiol 23: 2206-2214, 2013.

24. Galban CJ, Mukherji SK, Chenevert TL, Meyer CR, Hamstra DA, Bland PH, Johnson TD, Moffat BA, Rehemtulla A, Eisbruch A and Ross BD: A feasibility study of parametric response map analysis of diffusion-weighted magnetic resonance imaging scans of head and neck cancer patients for providing early detection of therapeutic efficacy. Transl Oncol 2: 184-190, 2009.

25. Vandecaveye V, Dirix P, De Keyzer F, Op de Beeck K, Vander Poorten V, Hauben E, Lambrecht M, Nuyts S and Hermans R: Diffusion-weighted magnetic resonance imaging early after chemoradiotherapy to monitor treatment response in head-and-neck squamous cell carcinoma. Int J Radiat Oncol Biol Phys 82: 1098-1107, 2012.

26. Kamitani T, Matsuo Y, Yabuuchi H, Fujita N, Nagao M, Jinnouchi M, Yonezawa M, Yamasaki Y, Tokunaga E, Kubo M, et al: Correlations between apparent diffusion coefficient values and prognostic factors of breast cancer. Magn Reson Med Sci 12: 193-199, 2013

27. Xue H, Ren C, Yang J, Sun Z, Li S, Jin Z, Shen K and Zhou W: Histogram analysis of apparent diffusion coefficient for the assessment of local aggressiveness of cervical cancer. Arch Gynecol Obstet 290: 341-348, 2014.

28. Downey K, Riches SF, Morgan VA, Giles SL, Attygalle AD, Ind TE, Barton DP, Shepherd JH and deSouza NM: Relationship between imaging biomarkers of stage I cervical cancer and poor-prognosis histologic features: Quantitative histogram analysis of diffusion-weighted MR images. AJR Am J Roentgenol 200: 314-320, 2013.

29. Ahn SJ, Choi SH, Kim YJ, Kim KG, Sohn CH, Han MH, Chang KH and Min HS: Histogram analysis of apparent diffusion coefficient map of standard and high B-value diffusion MR imaging in head and neck squamous cell carcinoma: A correlation study with histological grade. Acad Radiol 19: 1233-1240, 2012.

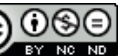

This work is licensed under a Creative Commons Attribution-NonCommercial-NoDerivatives 4.0 International (CC BY-NC-ND 4.0) License. 